\title{
VIOLENCE AGAINST DOCTORS- AN OVERVIEW
}

\author{
Shilekh Mittal1 ${ }^{1}$ Sonia Garg²
}

${ }^{1}$ Associate Professor, Department of Forensic Medicine, GGS Medical College, Faridkot.

${ }^{2}$ Associate Professor, Department of Physiology, GGS Medical College, Faridkot.

\begin{abstract}
BACKGROUND

These days violence against doctors is in the news frequently. Many reports concerning medical professionals of being assaulted, even killed by patients' disgruntled relatives. This violence is not limited to India, but situation seems to be similar in other countries all over the world. Among the various professions, medical professionals are among the most commonly being subjected to violence. Psychological distress is common in medical professionals who have experienced violence like depression, insomnia, post-traumatic stress disorder, agoraphobia and even a level of fear and/or anxiety that can cause work absenteeism. When we think how we can get rid of this situation, we must remember that practice of medicine is really about providing service, not just science. It is basically a combination of art, science and professionalism. The fundamentals of medicine are to care people with respect and dignity that are aimed at helping the sick through healing, alleviating suffering. This role of physician must be guided by the codes of ethics.
\end{abstract}

\section{KEYWORDS}

Violence, Against Doctors, Abuse, Assault.

HOW TO CITE THIS ARTICLE: Mittal S, Garg S. Violence against doctors- an overview. J. Evolution Med. Dent. Sci. 2017;6(33): 2748-2751, DOI: $10.14260 / J e m d s / 2017 / 592$

\section{BACKGROUND}

The instances of violence against doctors has no political boundaries; it is not limited to India. Among the various professions, medical professionals are among the most commonly being subjected to violence by the hands of patients and their relatives. British physicians have reported verbal abuse is most common than to physical violence. ${ }^{1}$ Between the years 1975 - 1990, in USA 106 healthcare workers lost their lives as a result of violence of which: 53 nurses, 27 pharmacists and 26 physicians, $57 \%$ of emergency room staff had been threatened by weapons. In Israel $90 \%$ of the support staff and $70 \%$ of the physicians working in a hospital emergency rooms have reported violent acts of which mostly are verbal abuse.2,3,4,5 In Australia 58\% of General Practitioners had experienced verbal abuse and 18\% experienced property damage. In Kuwait $86 \%$ of doctors had experienced verbal insults or imminent threat of violence, while $28 \%$ had experienced physical attacks of which $7 \%$ reported serious or fatal injury. In Pakistan, $77 \%$ of physicians had faced either verbal or physical abuse. In a retrospective exploratory cross-sectional study in a public sector healthcare facility in Lahore $74 \%$ of respondents were victims of violence, of which verbal abuse being the most common. Violence against healthcare professionals has also been reported from Saudi Arabia.6,7 More than 75\% of doctors in India have faced at least some form of violence as per IMA. ${ }^{8}$

Violence in hospitals occurs at various levels when patient comes in contact with health workers like during

Financial or Other, Competing Interest: None.

Submission 04-03-2017, Peer Review 09-04-2017,

Acceptance 15-04-2017, Published 24-04-2017.

Corresponding Author:

Dr. Shilekh Mittal,

Associate Professor,

Department of Forensic Medicine,

GGS Medical College, Faridkot, Punjab.

E-mail: shilekh@gmail.com

DOI: $10.14260 /$ jemds $/ 2017 / 592$ admission (explaining grave situations/bad prognosis, costly surgeries or treatment, anaphylactic reactions, unexpected consequences of the treatment, complications of the conditions, death), patient transportation (assaults may occur when service is denied, may be a doctor is not accompanying during shifting, patient dies before or during shifting, patient dies at tertiary centre on or after shifting), patient is involuntarily admitted, billing (not understanding the billing procedures, claiming overcharging, claiming unexplained or/and unwarranted charging, inability to pay charges, denial by hospital for treating the patient or giving the dead body for non-payment) or no proper information about hospital rules is not given to patient (advance payment, office permission, prescribing medicines, appliances and materials to be purchased from hospital only, etc.).

Emergency Departments are the most common place where violence is witnessed and the sources of violence are patient's relatives. ${ }^{6}$

The violence against doctors can be in the form of offensive language and abuses, threats of assaults, physical assaults, destruction of building, property and medical equipment and treatment of other patients or homicidal attacks. Some examples can be like: Threats- Expressions of intent to cause harm including verbal threats, threatening body language and written threats; Physical assaults- NonHarmful Attacks- Slapping, Blackening the face, Spitting, Pulling Hair, Shoving, Harmful- homicide and the use of weapons such as firearms or knives; Muggings- Aggravated assaults, usually conducted by surprise. ${ }^{6}$

In this perspective, we can only speculate regarding the cause of these heinous acts. That can be enumerated as-

\section{Physician Related}

1. Breakdown in physician-patient relationship; or utter disregard for the life and safety of the patient (poor and ineffective communication with the patient and his relatives).

2. Rude behaviour of the physician.

3. Less frequent house calls. 
4. Complex invasive procedures for diagnosis and treatment with resulting death or disability.

\section{Patient Related}

1. Unrealistic expectations of cure.

2. Poor compliance with medical recommendations.

3. Frequent self-destructive behaviour (heavy smoking, drinking, use of drugs, poor dietary management).

4. Increasing awareness of rights.

5. Comments on the treatment by another doctor.

6. Lack of consent.

7. Lack of documentation such as provisional diagnosis, relevant findings, etc.

8. Not taking second opinion whenever there is a problem and not informing relatives if patient is serious.

9. Misperception of physician's role in the society or his affluence. ${ }^{9,10,11,12}$

\section{Media Related}

Biased publicity of negligent suits and the size of awards. Newspapers project poor image of medical professionals has led the general people to believe that doctors are the villains, extortionists. (TV program like Satyamev Jayate by Amir Khan telling one-sided story only). On top of all, newspaper and electronic media play an important role by putting up negative reports about doctors, portraying them as the villains. Very often they misrepresent the facts while quoting only the patient's version of the incident and the physicians are not given one but important fundamental right of selfdefense. If newspapers publish reports about doctors saving lives, helping poor patients, it simply would not make saleable!!6,9,10,11,12,13

\section{Attorney Related}

There is lack of faith in judicial system, inactivity of the police and the impression that the police will take no action and can easily be bribed is another contributing factor. There are only one or two convictions of person known to have assaulted doctors till date and that also which are not well highlighted has led to this lawlessness among public. So it is not surprising that when patients or their attendants know that they can get away after assaulting a doctor, they are tempted to do so. $9,10,11,12$

\section{Economic}

1. Increased cost of medical care.

2. Payment by insurance companies.

\section{Social}

1. Mobile population.

2. Consumer's rights.

3. General increase in litigation. $9,10,11,12$

So, without any law, any trial, any conviction and no right of self-defense, helpless doctors are guilty as charged. Increasing commercialisation and dishonesty associated with wide spread unethical practices by the doctors has led to increased violence against the healthcare professionals, which has highlighted the importance of patient's satisfaction and patient safety. Patients take the matters in their own hands when the patients feel they have not been looked after properly and there is a wide gap that exists between the patient's expectations and the reality.6,14

Doctors who have been exposed to violence experienced high level of psychological distress like depression, insomnia, post-traumatic stress disorder, agoraphobia and even a level of fear and/or anxiety that can cause work absenteeism. Studies around the world show that acts of violence have a negative effect on the physician's family life and quality of life. In Kuwait $86 \%$ of the physicians who experienced violence had insomnia, depressions and other effects. A study in Israel showed that $36.2 \%$ of the physicians who were victims of violence had negative impact on their family life and quality of life. Physicians who were victims of aggression had a change in behaviour. Among the strategies followed by General Practitioners included defensive medicine like increasing prescribing, referring threatening patients to higher care centres and not taking threatening patients. The approach to work was changed due to violence or the fear of violence in $27 \%$ hospital doctors. $6,15,16$

When we think how we can get rid of this situation, we must remember that practice of medicine is really about providing service, not just science. It is basically a combination of art, science and professionalism. The fundamentals of medicine is aimed for helping the sick through healing, alleviating suffering and caring for people with respect and dignity. This role of physician must be guided by the codes of ethics governed behaviour.

The Lucky Doctors of the Past were treated like God and People Revered and Respected them,

1. Establish good rapport with the patient, also with patient's families with fellow physicians and with nursing and paramedical personnel, who may commit errors. The patient should be told of everything. Complications should be spotted out and treated.

2. Rationale: The doctor should use all available and relevant information to make diagnosis and formulate the treatment (history, physical examination, laboratory tests, x-rays, etc.). An error in Judgment is not negligence. Seek consultation where appropriate.

3. Maintain complete, accurate, legible medical records. Records are the most important evidence (diagnostic and therapeutic).

4. Obtain informed consent of the patient. Do not criticise any member of the treatment team in front of the patient. Do not criticise another physician.

5. Establish hospital injury prevention program. If an untoward result occurs, explain to the patient and treat it. Transfer the patient if the facility is incapable or inadequate to handle his problem. If a patient suffers damage due to negligence, it is better to compensate.

6. Respect: An attitude of care and concern, a relationship that suggest thoughtful professionalism and a humanistic approach many times solves problems. Treat the patient as the physician would wish himself or a member of his family to be treated.

7. Risks: Inform the patient of all side effects and anticipated risks. Risk must be identified carefully, controlled and managed to prevent injury to patient, i.e. good, desirable and achievable "patient care." The patient and his family told of the possible outcome of the treatment. Available alternatives and the result anticipated if nothing is done. 
8. Maintain good records on accidents, suicide, medication errors or problems.

9. Continuing education of physician.

10. Participation in medico-legal seminars. $9,10,11,12$

There is no single step that will protect doctors. In order to provide professional safety to doctors, the most important step is to make violence against doctors non-bailable offence. Since the press has taken a stand in opposition to members of medical profession, concept of medical press should be emphasised where we bring out our own news; we tell people our version of the truth. It must be ensured that only limited number of relatives should be allowed at the patient's bedside. Entry should be restricted strictly by passes and this must be implemented through good security. Periodic updating of the condition of the patient to the attendants is necessary like installing CCTV cameras in ICUs on each bed, so that attendants can see their patients and can get real time information. Healthcare professionals in general and junior doctors in particular, must develop proper communication skills and empathy. Every healthcare facility must have a liaison office to deal with the media and respond to their queries. Without permission, no media personnel should be allowed to enter the healthcare facilities and they should be briefed by the liaison officer or the hospital spokesman. Media in particular has to show responsibility while reporting health issues and those covering health must have some core knowledge of health issues. ${ }^{17}$

\section{Prevention Strategies for Doctors and to Develop a Safety and Health Program that Includes,}

1. Management commitment (Environment design): Develop emergency signalling, alarms and monitoring systems. Install security devices such as metal detectors to prevent armed persons from entering the hospital. Install security devices such as cameras, etc. Provide security escorts to the parking lots at night. Design the staff restrooms, nursing stations, waiting areas, reception areas and triage area and other public areas in hospital to minimise the risk of assault by making emergency exits, enclosed nurses' stations, deep service counters or bullet-resistant and shatterproof glass enclosures. Arrange furniture and other objects to minimise their use as weapons. To minimise patient waiting time, staffing patterns should be designed to prevent personnel from working alone. By cardcontrolled access, which can restrict the movement of the public in hospitals. Installing alarms for alerting security personnel when violence is threatened.

2. Employee participation: Provide all workers with training in recognising and managing assaults, resolving conflicts and maintaining hazard awareness and understanding the practical and legal consequences of the behaviour.

3. Hazard identification.

4. Safety and health training with knowledge of medicolegal implications of the behaviour: Violence may occur in the workplace in spite of preventive measures. Employers should be prepared to deal with the consequences of this violence by providing an environment that promotes open communication and by developing written procedures for reporting and responding to violence. Employers should offer and encourage counselling whenever a worker is threatened or assaulted.

5. Hazard prevention, control and reporting.

Safety tips for health workers with impending violence: Verbally expressed anger and frustration, body language such as threatening gestures, signs of drug or alcohol use, presence of a weapon should be watched.2,910,11,12,17,18

In Detroit hospital by installing security screening system (stationary metal detectors supplemented by hand-held units) had prevented the entry of 33 handguns, 1,324 knives and 97 mace-type sprays during a 6-month period. In New York City hospital, making restrictive movement of visitors by using identification badges and colour-coded passes to limit each visitor to a specific floor reduced the number of reported violent crimes by $65 \%$ in about 18 months. 18

\section{CONCLUSION}

There is an urgent need to make the healthcare facilities a safe environment for the healthcare professionals to work, only then they can be expected to work with devotion and dedication. Breaking news on the Television Channels regarding death of patients due to doctor's negligence has only served to work against the patient's own interest, as now the healthcare professionals are very reluctant to handle serious cases; hence, many precious lives which could have been saved are being lost.

Predicting the human nature is not easy. So even after taking all these steps, things still can go wrong and in that case, we cannot but agree with P Madhok who wrote "There is something to be said for young doctors who should learn martial arts. The world is increasingly progressing towards violence. So karate, taekwondo and other martial arts are worthwhile learning for self-defense. It will boost the doctor's confidence even if not used." 6,19

\section{REFERENCES}

[1] Ness GJ, House A, Ness AR. Aggression and violent behaviour in general practice: population based survey in the north of England. British Medical Journal 2000;320(7242):1447-8.

[2] Khan MAI, Ahasan HN, Mahbub S, et al. Violence against doctors. J Medicine 2010;11:167-9.

[3] Paola F, Malik T, Qureshi A. Violence against physicians. J Gen Intern Med 1994;9(9):503-6.

[4] Derazon H, Nissimian S, Yosefy C, et al. Violence in the emergency department. Harefuah 1999;137(3-4):95101.

[5] Arimatsu M, Wada K, Yoshikawa T, et al. An epidemiological study of work-related violence experienced by physicians who graduated from a medical school in Japan. J Occup Health 2008;50(4):357-361.

[6] Jawaid SA. Patient satisfaction, patient safety and increasing violence against healthcare professionals. Pak J Med Sci 2015;31(1):1-3.

[7] Algwaiz WM, Alghanim SA. Violence exposure among healthcare professionals in Saudi public hospitals. A preliminary investigation. Saudi Med J 2012;33(1):7682. 
[8] Dey S. Over $75 \%$ of doctors have faced violence at work, study finding. May 4, 2015. http://timesofindia.indiatimes.com/india/Over-75-ofdoctors-have-face... on 23-07-2016

[9] Reddy NKS, Murty OP. Medical law and ethics. The essentials of forensic medicine and toxicology. 33rd edn. Jaypee Brothers Medical Publishers 2014:24-56.

[10] Vij K. Medical education vis-à-vis medical practice. Textbook of forensic medicine and toxicology principles and practice. $5^{\text {th }}$ edn. New Delhi: Elsevier 2011:346-60.

[11] Dogra TD, Rudra A. Physician patient relationship. Lyons medical jurisprudence \& toxicology. $1^{\text {st }}$ edn. Delhi: Delhi Law House 2016:17-40.

[12] Dogra TD, Rudra A. Professional negligence. Lyons medical jurisprudence \& toxicology. 11th edn. Delhi: Delhi Law House 2007:307-45.
[13] National Union of Public Employees. Violence in the NHS. Hlth Serv News 1991: April 4.

[14] Nazmul Ahasan HAM, Das A. Violence against doctors. J Medicine 2014;15(2):106-8.

[15] Myerson S. Violence to general practitioners and fear of violence. Fam Pract 1991;8(2):145-7.

[16] Hobbs FDR. General practitioners' changes to practice due to aggression at work. Fam Pract 1994;11(1):75-9.

[17] Gupta MC. What should doctors and nursing homes do to prevent and manage violence by patients/relatives? Indian Journal of Clinical Practice 2012;22(9):470-2.

[18] CDC. Violence: occupational hazards in hospitals. USA. DHHS (NIOSH) Publication No. 2002-101 April 2002.

[19] Madhok P. Violence against doctors. Bombay Hospital Journal 2009;51(2):301-2. 